\title{
Armazenamento de sementes tratadas com cloreto de mepiquat e desenvolvimento de plântulas de algodoeiro
}

\author{
Processing of seeds treated with mepiquat chloride and the development of cotton seedlings
}

\begin{abstract}
Eliege Aparecida de Paiva Oliveira ${ }^{\mathrm{I}}$ Claudemir Zucareli ${ }^{\mathrm{I}}{ }^{*}$ André Mateus Prando ${ }^{\mathrm{I}}$ Celso Jamil Marur ${ }^{\mathrm{III}}$ Alberto Sérgio do Rego Barros ${ }^{\mathrm{III}}$ Getúlio Takashi Nagashima ${ }^{\mathrm{III}}$ Inês Cristina de Batista Fonseca ${ }^{\mathrm{II}}$
\end{abstract}

\section{RESUMO}

O tratamento de sementes de algodão com regulador de crescimento é utilizado para a obtenção de plantas com menor estatura, com a vantagem de assegurar o controle do desenvolvimento vegetativo desde a emergência. O objetivo deste trabalho foi avaliar o desenvolvimento de plântulas de algodoeiro, provenientes de sementes tratadas com cloreto de mepiquat, em diferentes doses, formas de aplicação e armazenadas após o tratamento. Sementes da cultivar 'IPR 120' foram tratadas com soluções de cloreto de

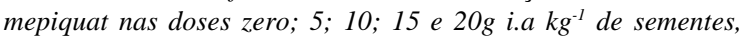
via embebição por 12 horas e via aplicação direta nas sementes. As sementes tratadas foram armazenadas em condições ambientais de laboratório e avaliadas mensalmente até 180 dias. Foram avaliados germinação, comprimentos da parte aérea, radicular e total e a massa seca das plântulas. Os dados, para cada período de armazenamento, foram submetidos à análise de variância e as médias de formas de aplicação comparadas pelo teste de Tukey a 5\%, em delineamento inteiramente casualizado, com quatro repetições, em esquema fatorial de $5 \times 2$ (doses $x$ formas de aplicação). Os dados de doses foram submetidos a estudos de regressão até $2^{\circ}$ grau. Sementes tratadas com cloreto de mepiquat, independente da forma e dose utilizada podem ser armazenadas por até 180 dias após o tratamento sem comprometer o processo de germinação e a ação do regulador de crescimento. O tratamento via embebição de sementes com o cloreto de mepiquat proporciona maior redução do crescimento da plântula em relação à aplicação direta. O incremento nas doses de cloreto de mepiquat provoca a redução no crescimento $e$ desenvolvimento das plântulas de algodoeiro, proporcionando menor comprimento e massa seca.

Palavras-chave: Gossypium hirsutum L., regulador vegetal, embebição e formas de aplicação.

\section{ABSTRACT}

The treatment of cotton seeds with growth regulator is used to obtain plants with reduced stature, with the advantage of ensuring control of plant development from emergence. The objective was to evaluate the development of cotton seedlings, grown from seeds treated with chloride mepiquat at different doses, application forms and stored after treatment. The seeds were treated with ' 120 IPR' solutions mepiquat chloride at doses of zero, 5, 10, 15 and $20 \mathrm{~g} \mathrm{a.} \mathrm{i} \mathrm{kg-1}$ seed, via soaking for 12 hours and via direct application in seed. The treated seeds were stored in laboratory conditions and evaluated monthly until 180 days. We evaluated the germination, the length of shoot, root and total, the dry weight of seedlings. The data for each storage period, were subjected to analysis of variance and means of application methods were compared by Tukey test at 5\%, under the completely randomized design with four replications in a factorial $5 \times 2$ (doses $x$ application forms). The data were subjected to doses of regression studies until 2nd grade. Seeds treated with mepiquat chloride, independent of dose and can be stored for up to 180 days after treatment, without compromising the process of germination and growth regulator action. Treatment via soaking of seeds with mepiquat chloride provides the greatest reduction in seedling growth in relation to direct application. The increased rate of mepiquat chloride causes the reduction the growth and development of cotton seedlings, providing less length and dry mass.

Key words: Gossypium hirsutum L., growth regulator, imbibition and application forms.

IPrograma de Pós-graduação em Agronomia, Universidade Estadual de Londrina (UEL), Londrina, PR, Brasil.

IIDepartamento de Agronomia, Centro de Ciências Agrárias (CCA), UEL, CP 6001, 86051-990, Londrina, PR, Brasil. E-mail: claudemircca@uel.br. Autor para correspondência.

IIIInstituto Agronômico do Paraná (IAPAR), Londrina, PR, Brasil. 


\section{INTRODUÇÃO}

Diante de significativas mudanças no sistema de produção da cultura do algodoeiro e com a sua consolidação em áreas tecnificadas com colheita mecanizada, a manipulação da arquitetura das plantas com uso de reguladores de crescimento é uma das estratégias agronômicas incorporadas no sistema de produção, com o objetivo de buscar melhoria nos atuais níveis de produtividade com redução de custos (LAMAS et al., 2000).

No mercado, há vários reguladores de crescimento, dentre eles o cloreto de mepiquat (cloreto 1,1-dimetil piperidíneo), comercialmente denominado Pix (GUTHRIE et al., 1995), que inibe a biossíntese do ácido giberélico, resultando em redução do crescimento, em razão do menor alongamento celular (LAMAS, 2001).

A aplicação de redutores de crescimento, usualmente, é realizada via foliar durante o desenvolvimento vegetativo da planta, pois as recomendações de formas e doses de aplicação do cloreto de mepiquat devem ser específicas, pois cada cultivar de algodoeiro herbáceo, intrinsecamente detém particularidades próprias quanto à absorção de substâncias reguladoras de crescimento vegetal (SOUZA et al., 2005).

Entre os métodos utilizados para a aplicação de regulador de crescimento em algodoeiro, o tratamento de sementes com soluções contendo o fitorregulador cloreto de mepiquat tem sido pesquisado. A vantagem desta metodologia, em relação à aplicação foliar, é assegurar o controle do desenvolvimento vegetativo desde a emergência, independente de condições adversas para a pulverização, como ocorrência de chuvas após a aplicação do produto, o que faz com que ele seja lavado antes de ser completamente absorvido pela planta (MATEUS et al., 2004, NAGASHIMA et al., 2005). O tratamento das sementes pode ser realizado tanto via aplicação direta do produto externamente à semente, como por embebição em solução contendo o regulador de crescimento.

O uso da embebição de sementes de algodão com cloreto de mepiquat é uma técnica para a obtenção de plantas com menor estatura (NAGASHIMA et al., 2005; NAGASHIMA et al., 2007; NAGASHIMA et al., 2009; NAGASHIMA et al., 2010). Porém, há poucas informações relacionadas ao tratamento de sementes de algodão com reguladores de crescimento abordando os efeitos do produto sobre a germinação e o desenvolvimento de plântulas provenientes de sementes armazenadas após o tratamento, bem como os efeitos das formas de aplicação do produto e doses utilizadas.
Ao estudar o efeito do tratamento de sementes de algodão embebidas em diferentes doses (2,5; 5,0 e 10,0g i.a. $\mathrm{kg}^{-1}$ de sementes) de cloreto de mepiquat, NAGASHIMA et al. (2010) constataram redução significativa no comprimento total das plântulas, no entanto não houve efeito no comprimento da radícula, comprovando que a embebição reduz a altura da planta já a partir da fase de plântula, sem causar efeito negativo no processo de germinação.

No entanto, tratamentos de sementes com produtos químicos como o regulador de crescimento cloreto de mepiquat, previamente ao armazenamento, podem contribuir para acelerar o processo de deterioração e, ainda, poderão ter seu efeito anulado em virtude do período e condições de armazenagem. Em adição, o efeito do redutor de crescimento sobre o desenvolvimento de plântulas de sementes armazenadas pode ser variável de acordo com as doses e formas de aplicação.

Diante do exposto, o objetivo deste trabalho foi avaliar o desenvolvimento de plântulas de algodoeiro, provenientes de sementes tratadas com cloreto de mepiquat, em diferentes doses, formas de aplicação e armazenadas após o tratamento.

\section{MATERIAL E MÉTODOS}

O experimento foi conduzido no Laboratório de Análise de Sementes do Instituto Agronômico do Paraná (IAPAR), Londrina-PR, em delineamento experimental inteiramente casualizado, em esquema fatorial 5x2, correspondente a cinco doses de cloreto de mepiquat e duas formas de aplicação (embebição e aplicação direta), totalizando 10 tratamentos, com quatro repetições.

Foram utilizadas sementes de algodão da cultivar IPR 120 deslintadas quimicamente com ácido sulfúrico. Para o tratamento via embebição, as sementes foram tratadas em solução de cloreto de mepiquat ( $250 \mathrm{~g}$ i.a. $\mathrm{L}^{-1}$ ) nas doses zero; 5; 10; 15 e 20 g i.a. $\mathrm{kg}^{-1}$ de sementes, por um período de 12 horas a $20 \pm 0,5^{\circ} \mathrm{C}$, sendo utilizados $400 \mathrm{~mL}$ de solução por kg de sementes. No tratamento via aplicação direta, foram utilizadas as mesmas doses do regulador de crescimento, as sementes foram acondicionadas em um saco plástico com 100mL de solução por kg de sementes, procedendo à agitação até distribuição uniforme do produto.

Após a aplicação do regulador, as sementes foram secas à sombra em local ventilado, acondicionadas em sacos de papel tipo Kraft e armazenadas por 180 dias, em condições ambientais. Os dados médios de temperatura (máxima de $25,5^{\circ} \mathrm{C}$ e 
mínima $21,0^{\circ} \mathrm{C}$ ) e umidade relativa (máxima de $86,5 \%$ e mínima 65,5\%), durante o período de armazenamento, foram registrados com aparelho termohigrógrafo modelo R-704.

As avaliações foram realizadas mensalmente, até os 180 dias após o armazenamento, determinando-se as seguintes características: germinação: quatro repetições de 50 sementes foram distribuídas em rolo de papel Germitest, umedecido com água destilada, na proporção de 2,5 vezes a massa do papel seco, em germinador a $25^{\circ} \mathrm{C}$. A avaliação foi realizada aos quatro e sete dias após a instalação do teste (BRASIL, 2009); comprimento de plântulas: o método utilizado foi o do rolo de papel, umedecido na proporção de 2,5 vezes o volume de água em relação à massa do papel seco, descritos por NAKAGAWA (1999), adaptado de AOSA (1983). As sementes foram depositadas sobre duas folhas de papel, distribuídas ao longo de uma linha traçada no terço superior do papel, utilizando 10 sementes, com quatro repetições. Aseguir, foram cobertas com uma terceira folha de papel, enroladas e protegidas por saco plástico. Quatro dias após a instalação, foram avaliadas as plântulas normais, o comprimento da radícula, parte aérea e total de plântulas; massa seca de plântulas: utilizou-se a mesma metodologia descrita anteriormente, sendo as plântulas normais acondicionadas em sacos de papel e levadas à estufa de circulação de ar forçado a $65 \pm 5^{\circ} \mathrm{C}$ até massa constante.

Os dados, para cada período de armazenamento, foram submetidos à análise de variância e as médias de formas de aplicação comparadas pelo teste de Tukey a 5\%. Os dados de doses foram submetidos a estudos de regressão até $2^{\circ}$ grau.

\section{RESULTADOS E DISCUSSÃO}

O efeito da forma de aplicação foi constatado nas avaliações de germinação (GERM.) somente aos 90 dias e, no comprimento de radícula (CRP), comprimento de parte aérea (CPAP) e comprimento total de plântulas (CTP) de algodoeiro, nos períodos de zero a 90 dias após o armazenamento (DAA). A partir de 120 dias, o efeito de forma de aplicação não foi observado nestas variáveis, assim como para massa seca de plântulas (MSP) em todo período estudado (Tabela1).

Para as doses do regulador de crescimento utilizadas no tratamento de sementes de algodoeiro, observou-se efeito significativo independente da forma de aplicação, mantendo efeito redutor para a maioria das características avaliadas até aos 150 dias. Para a porcentagem de germinação, o efeito significativo foi observado somente aos 30 dias de armazenamento. Em relação ao comprimento total de plântulas, o efeito redutor permaneceu até aos 180 dias. Entre os fatores formas de aplicação e doses de cloreto de mepiquat, para a maioria das avaliações realizadas, ocorreu interação no período de zero (sementes não armazenadas), sendo que, nos demais períodos, verificaram-se interação apenas para massa seca de plântulas aos 120 e 180 dias (Tabela1).

A aplicação direta (A.D.) de cloreto de mepiquat favoreceu a porcentagem de germinação somente no período de 90 dias de armazenamento. No comprimento de raiz de plântulas (CRP) de algodoeiro, nos períodos de zero a 90 dias, observou-se maior redução com tratamento via embebição (EMB.) em relação à aplicação direta. YEATES et al. (2005), ao avaliar, em condições de campo, o efeito do tratamento de sementes com cloreto de mepiquat via embebição por 2,5 horas e aplicação direta do produto, verificaram que o método da embebição causou o dobro da redução da altura, quando comparado com o método da aplicação direta.

Nos demais períodos, não se verificaram diferenças no comprimento de raiz das plântulas de algodão quanto à forma de aplicação do produto nas sementes (Tabela 2). NAGASHIMA et al. (2005) verificaram que o tratamento de sementes de algodão com o cloreto de mepiquat reduziu o crescimento da parte aérea e sistema radicular, mas, apesar de vantajosa do ponto de vista operacional, a embebição de sementes pode ocasionar diminuição na velocidade de crescimento de raízes em sua fase inicial.

O tratamento de sementes com o cloreto de mepiquat, independentemente da dose utilizada manteve a capacidade germinativa das sementes acima de $80 \%$ em todos dos períodos avaliados. Resultados diferentes foram obtidos por NAGASHIMA et al. (2010), que, mesmo utilizando doses menores que as deste estudo, observaram redução da viabilidade das sementes tratadas com cloreto de mepiquat após 60 dias de armazenamento.

O comprimento de raiz de plântulas de algodoeiro diminuiu em função do aumento das doses de cloreto de mepiquat, independentemente da forma de tratamento utilizada, desde o período zero até aos 150 dias (Tabela 2). Os dados de comprimento de raiz das plântulas, em função das doses utilizadas no período zero das sementes tratadas, ajustaram-se ao modelo quadrático, com ponto de mínima resposta de 8,40g i.a. $\mathrm{kg}^{-1}$. Nos períodos de 30 a 150 dias, os ajustes ocorridos foram de natureza linear decrescente com o incremento das doses, o que também foi verificado aos 30 dias para a característica de germinação (Tabela 2). Tais resultados diferem dos obtidos por NAGASHIMA et al. (2010), que não constataram redução no 
Tabela 1 - Resumo da análise de variância (Prob.>F) para germinação (GERM \%), comprimento da radícula de plântulas (CRP - cm), comprimento de parte aérea de plântulas (CPAP - cm), comprimento total de plântulas (CTP - cm) e massa de matéria seca de plântulas (MSP - g), originadas de sementes de algodoeiro, cultivar IPR 120, tratadas com Cloreto de Mepiquat em função de formas e doses em diferentes períodos de armazenamento.

\begin{tabular}{|c|c|c|c|c|c|}
\hline \multirow{2}{*}{ F. A. } & \multirow[b]{2}{*}{ GERM } & \multirow[b]{2}{*}{ CRP } & \multirow[b]{2}{*}{ CPAP } & \multirow[b]{2}{*}{ СТP } & \multirow[b]{2}{*}{ MSP } \\
\hline & & & & & \\
\hline Formas & $0,066^{\mathrm{ns}}$ & $0,001 * *$ & $0,004^{* *}$ & $0,001 * *$ & $0,302^{\mathrm{ns}}$ \\
\hline Doses & $0,946^{\mathrm{ns}}$ & $0,003^{* *}$ & $0,005^{* *}$ & $0,001 * *$ & $0,217^{\text {ns }}$ \\
\hline Formas $\mathrm{x}$ doses & $0,840^{\mathrm{ns}}$ & $0,123^{\mathrm{ns}}$ & $0,032 *$ & $0,023^{* *}$ & $0,014^{*}$ \\
\hline CV (\%) & 4, 91 & 10,13 & 12,02 & 6,61 & 21,60 \\
\hline Formas & \multicolumn{5}{|c|}{ 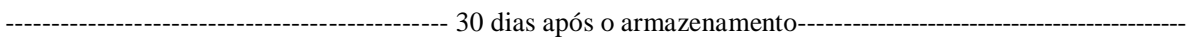 } \\
\hline Doses & $0,042^{*}$ & $0,001^{* *}$ & $0,005^{* *}$ & $0,001^{* *}$ & $0,744^{\mathrm{ns}}$ \\
\hline Formas x Doses & $0,324^{\mathrm{ns}}$ & $0,307^{\mathrm{ns}}$ & $0,252^{\mathrm{ns}}$ & $0,103^{\mathrm{ns}}$ & $0,541^{\text {ns }}$ \\
\hline CV $(\%)$ & 3,57 & 9,70 & 11,64 & 10,39 & 24,48 \\
\hline Formas & \multicolumn{5}{|c|}{ 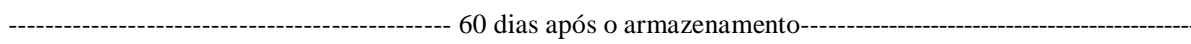 } \\
\hline Doses & $0,074^{\mathrm{ns}}$ & $0,005^{* *}$ & $0,048^{*}$ & $0,001^{* *}$ & $0,367^{\text {ns }}$ \\
\hline Formas x Doses & $0,446^{\mathrm{ns}}$ & $0,296^{\mathrm{ns}}$ & $0,280^{\mathrm{ns}}$ & $0,507^{\mathrm{ns}}$ & $0,786^{\mathrm{ns}}$ \\
\hline CV $(\%)$ & 4, 96 & 10,79 & 12,85 & 6, 71 & 17,86 \\
\hline Formas & $0,032 *$ & $0,020^{*}$ & $\begin{array}{l}\text { apos o arm } \\
0,007^{* *}\end{array}$ & $0,006^{* *}$ & $0,542^{\mathrm{ns}}$ \\
\hline Doses & $0,485^{\mathrm{ns}}$ & $0,001^{* *}$ & $0,029 *$ & $0,003^{* *}$ & $0,158^{\mathrm{ns}}$ \\
\hline Formas x Doses & $0,851^{\mathrm{ns}}$ & $0,710^{\mathrm{ns}}$ & $0,286^{\mathrm{ns}}$ & $0,329^{\mathrm{ns}}$ & $0,790^{\mathrm{ns}}$ \\
\hline CV (\%) & 5,90 & 6,99 & 12,54 & 10,57 & 16,93 \\
\hline Formas & \multicolumn{5}{|c|}{ 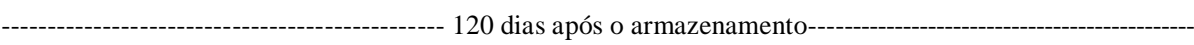 } \\
\hline Doses & $0,087^{\mathrm{ns}}$ & $0,001^{* *}$ & $0,001^{* *}$ & $0,001^{* *}$ & $0,054^{\mathrm{ns}}$ \\
\hline Formas x Doses & $0,732^{\mathrm{ns}}$ & $0,111^{\mathrm{ns}}$ & $0,549^{\mathrm{ns}}$ & $0,073^{\mathrm{ns}}$ & $0,045^{*}$ \\
\hline CV (\%) & 5,58 & 12,00 & 12,41 & 9, 93 & 24,21 \\
\hline Formas & \multicolumn{5}{|c|}{ 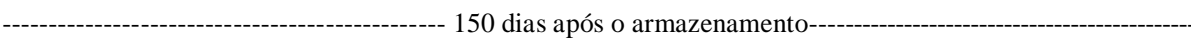 } \\
\hline Doses & $0,790^{\mathrm{ns}}$ & $0,001^{* *}$ & $0,033^{*}$ & $0,001^{* *}$ & $0,182^{\mathrm{ns}}$ \\
\hline Formas x Doses & $0,957^{\mathrm{ns}}$ & $0,186^{\mathrm{ns}}$ & $0,118^{\mathrm{ns}}$ & $0,074^{\mathrm{ns}}$ & $0,415^{\text {ns }}$ \\
\hline CV $(\%)$ & 6, 09 & 10,80 & 11,60 & 9,58 & 24,68 \\
\hline \multicolumn{6}{|c|}{ 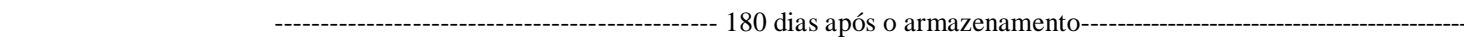 } \\
\hline Doses & $0,563^{\text {ns }}$ & $0,869^{\mathrm{ns}}$ & $0,986^{\mathrm{ns}}$ & $0,001^{* *}$ & $0,196^{\mathrm{ns}}$ \\
\hline Formas x Doses & $0,647^{\mathrm{ns}}$ & $0,187^{\mathrm{ns}}$ & $0,260^{\mathrm{ns}}$ & $0,078^{\mathrm{ns}}$ & $0,046^{*}$ \\
\hline CV (\%) & 5,19 & 9, 92 & 12,17 & 7,20 & 19,81 \\
\hline
\end{tabular}

* e ${ }^{* *}$ - significativo a 5 e $1 \%$ de probabilidade, respectivamente. ${ }^{\text {ns }}$ - não significativo.

comprimento da raiz de plântulas de algodoeiro oriundas de sementes embebidas por 12 horas em soluções contendo cloreto de mepiquat nas doses zero; 2,5; 5,0 e $10 \mathrm{~g}$ i.a kg-1 de sementes. LAMAS et al. (2000), ao conduzir experimento em condições de campo, verificaram que esse regulador de crescimento além de reduzir o desenvolvimento da parte aérea também modificou os padrões radiculares.

Na avaliação do comprimento da parte aérea de plântulas (CPAP) no período zero, foi constatada interação entre os fatores formas de aplicação e doses de cloreto de mepiquat (Tabela 3). Com os resultados em função de forma e doses de cloreto de mepiquat utilizadas no período zero, verificou-se ajuste dos valores com tendência linear decrescente para ambos os tratamentos. Nas avaliações realizadas aos 30, 60 e 90 dias após o armazenamento, observaram-se diferenças significativas para a forma de aplicação e doses utilizadas, porém, nas avaliações realizadas aos 120 e 150 dias, o efeito foi somente de doses, com ajuste 
Tabela 2 - Valores médios de germinação (GERM - \%), comprimento da radícula de plântulas (CRP - cm), comprimento de parte aérea de plântulas (CPAP - cm), comprimento total de plântulas (CTP - cm) e massa de matéria seca de plântulas (MSP - g), originadas de sementes da cultivar IPR 120, tratadas com cloreto de mepiquat.

\begin{tabular}{|c|c|c|c|c|c|c|c|c|c|c|c|c|}
\hline \multirow{2}{*}{ Variáveis } & \multicolumn{2}{|c|}{------Formas------- } & \multicolumn{5}{|c|}{---------Doses (g i. a. kg-1)---------- } & \multirow[b]{2}{*}{ Equações de Regressão } & \multirow[b]{2}{*}{$\mathrm{R}^{2}$} & \multirow[b]{2}{*}{ P. Máx. } & \multirow[b]{2}{*}{ P. Mín. } & \multirow[b]{2}{*}{$\mathrm{CV} \%$} \\
\hline & EMB. & A. D. & 0 & 5 & 10 & 15 & 20 & & & & & \\
\hline GERM & $80 a$ & $83 a$ & 82 & 82 & 81 & 80 & 81 & - & - & - & - & 4,91 \\
\hline CRP & 8 a & $9 \mathrm{~b}$ & 9 & 9 & 8 & 7 & 8 & $Y=12,249-0,185 x+0,011 x^{2}$ & 76,98 & - & 8,40 & 12,02 \\
\hline GERM & $80 a$ & $82 a$ & 89 & 91 & 88 & $\begin{array}{l}-30 \text { dias } \\
86\end{array}$ & $\begin{array}{l}\text { após o a } \\
87\end{array}$ & $\begin{array}{l}\mathrm{Y}=89,900-0,170 \mathrm{x} \\
\mathrm{Y}=\mathrm{y}\end{array}$ & 51,42 & - & - & 3,57 \\
\hline CRP & $10 \mathrm{a}$ & $11 \mathrm{~b}$ & 11 & 11 & 11 & 10 & 10 & $Y=11,486-0,087 x$ & 83,68 & - & - & 11,60 \\
\hline CPAP & $3 \mathrm{a}$ & $4 \mathrm{~b}$ & 5 & 4 & 3 & 3 & 3 & $Y=4,517-0,155 x$ & 99,73 & - & - & 9,58 \\
\hline СТP & $11 \mathrm{a}$ & $12 \mathrm{~b}$ & 16 & 15 & 14 & 13 & 13 & $Y=15,863-0,179 x$ & 95,82 & - & - & 10,80 \\
\hline MSP & $0,450 \mathrm{a}$ & 0,430 a & 0,459 & 0,439 & 0,454 & 0,510 & 0,370 & - & - & - & - & 24,68 \\
\hline GERM. & $87 a$ & $87 a$ & 88 & 91 & 86 & 85 & 86 & 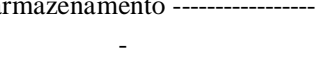 & - & - & - & 4,96 \\
\hline CRP & $12 \mathrm{a}$ & $13 b$ & 13 & 13 & 13 & 12 & 9 & $Y=12,249-0,185 x$ & 76,98 & - & - & 12,02 \\
\hline CPAP & $5 a$ & $6 b$ & 8 & 7 & 5 & 5 & 8 & $Y=2,328-0,071 x-0,002 x^{2}$ & 99,56 & 17,75 & - & 6,61 \\
\hline СТР & $17 \mathrm{a}$ & $19 b$ & 21 & 20 & 18 & 17 & 17 & $Y=7,992-0,187 x$ & 94,55 & - & - & 0,13 \\
\hline MSP & 0,430a & $0,460 \mathrm{a}$ & 0,483 & 0,453 & 0,429 & 0,484 & 0,383 & - & - & - & - & 21,60 \\
\hline GERM & $84 a$ & $88 b$ & 83 & 87 & 85 & 87 & 86 & - & - & - & - & 5,90 \\
\hline CRP & $9 \mathrm{a}$ & $10 \mathrm{~b}$ & 11 & 10 & 9 & 9 & 8 & $Y=5,519-0,042 x$ & 69,13 & - & - & 11,64 \\
\hline CPAP & $4 a$ & $5 \mathrm{~b}$ & 8 & 6 & 7 & 7 & 8 & $Y=2,231-0,069 x-0,002 x^{2}$ & 99,05 & 17,25 & - & 10,39 \\
\hline СРT & $13 a$ & $15 b$ & 18 & 16 & 16 & 16 & 15 & $Y=7,722-0,064 x$ & 70,05 & - & - & 10,57 \\
\hline MSP & $0,410 \mathrm{a}$ & 0,410 a & 0,399 & 0,440 & 0,404 & 0,395 & 0,456 & - & - & - & - & 24,48 \\
\hline GERM & $86 a$ & $88 a$ & 97 & 81 & 84 & $\begin{array}{l}120 \text { dia } \\
86\end{array}$ & $\begin{array}{l}\text { após o } \\
86\end{array}$ & $\begin{array}{c}\text { armazenamento ------ } \\
-\end{array}$ & - & - & - & 5,58 \\
\hline CRP & $4 a$ & $4 a$ & 10 & 9 & 8 & 7 & 6 & $Y=9,44-0,149 x$ & 96,42 & - & - & 12,17 \\
\hline CPAP & $2 \mathrm{a}$ & $2 \mathrm{a}$ & 7 & 5 & 3 & 2 & 2 & $Y=2,128-0,016 x$ & 94,32 & - & - & 7,20 \\
\hline СТP & $6 a$ & $7 \mathrm{~b}$ & 17 & 13 & 11 & 9 & 8 & $Y=13,634-0,257 x$ & 96,60 & - & - & 9,92 \\
\hline GERM & $87 a$ & $90 a$ & 91 & 88 & 89 & 88 & 88 & - & - & - & - & 6,09 \\
\hline CRP & $4 a$ & $5 a$ & 11 & 11 & 11 & 10 & 10 & $Y=15,863-0,179 x$ & 95,82 & - & - & 12,85 \\
\hline CPAP & За & $5 b$ & 5 & 4 & 3 & 3 & 3 & $Y=4,517-0,155 x$ & 99,73 & - & - & 9,58 \\
\hline СTP & $10 \mathrm{a}$ & $12 b$ & 16 & 15 & 14 & 13 & 13 & $Y=176,946-4,475 x$ & 98,90 & - & - & 10,80 \\
\hline MSP & 0,430a & $0,400 \mathrm{a}$ & 0,439 & 0,419 & 0,451 & 0,416 & 0,378 & - & - & - & - & 17,86 \\
\hline GERM & $82 a$ & $84 a$ & 85 & 85 & 82 & $\begin{array}{l}180 \text { dia } \\
84\end{array}$ & $\begin{array}{l}\text { após o } \\
83\end{array}$ & $\begin{array}{c}\text { armazenamento ---- } \\
-\end{array}$ & - & - & - & 5,19 \\
\hline CRP & $5 a$ & $5 a$ & 6 & 5 & 5 & 5 & 5 & - & - & - & - & 12,54 \\
\hline CPAP & $2 \mathrm{a}$ & $5 \mathrm{~b}$ & 4 & 3 & 2 & 2 & 2 & $Y=2,231-0,069 x$ & 99,05 & - & - & 6,99 \\
\hline СТP & $7 \mathrm{a}$ & $7 \mathrm{a}$ & 10 & 8 & 7 & 7 & 7 & $Y=7,722-0,064 x$ & 70,05 & - & - & 10,57 \\
\hline
\end{tabular}

Médias seguidas de mesma letra na linha não diferem pelo teste de Tukey a 5\% de probabilidade. Embebição (EMB.); Aplicação Direta (A.D.).

linear decrescente aos 30, 120, 150 e 180 dias. Aos 60 e 90 dias, os dados ajustaram-se a uma equação quadrática, com comprimento máximo da parte aérea de 17,75 e 17,25cm, respectivamente (Tabela 2). A diminuição do porte da plântula foi mais significativa, principalmente, nas maiores doses. NAGASHIMA et al. (2005) obtiveram redução na altura da planta de algodão diretamente proporcional ao incremento da dose aplicada de cloreto de mepiquat.

As diferenças no comprimento total de plântulas foram significativas quanto à forma de aplicação e doses utilizadas de cloreto de mepiquat com ajustes lineares decrescente nos períodos de 30 , 60, 90 dias. O efeito das doses foi constatado nos 
Tabela 3 - Interação entre formas (FA) e doses para médias de comprimento de parte aérea de plântulas (CPAP - cm), comprimento total de plântulas (CTP - cm) e massa de matéria seca de plântulas (MSP - g), oriundos de sementes de algodoeiro, cultivar IPR 120 tratadas com cloreto de mepiquat.

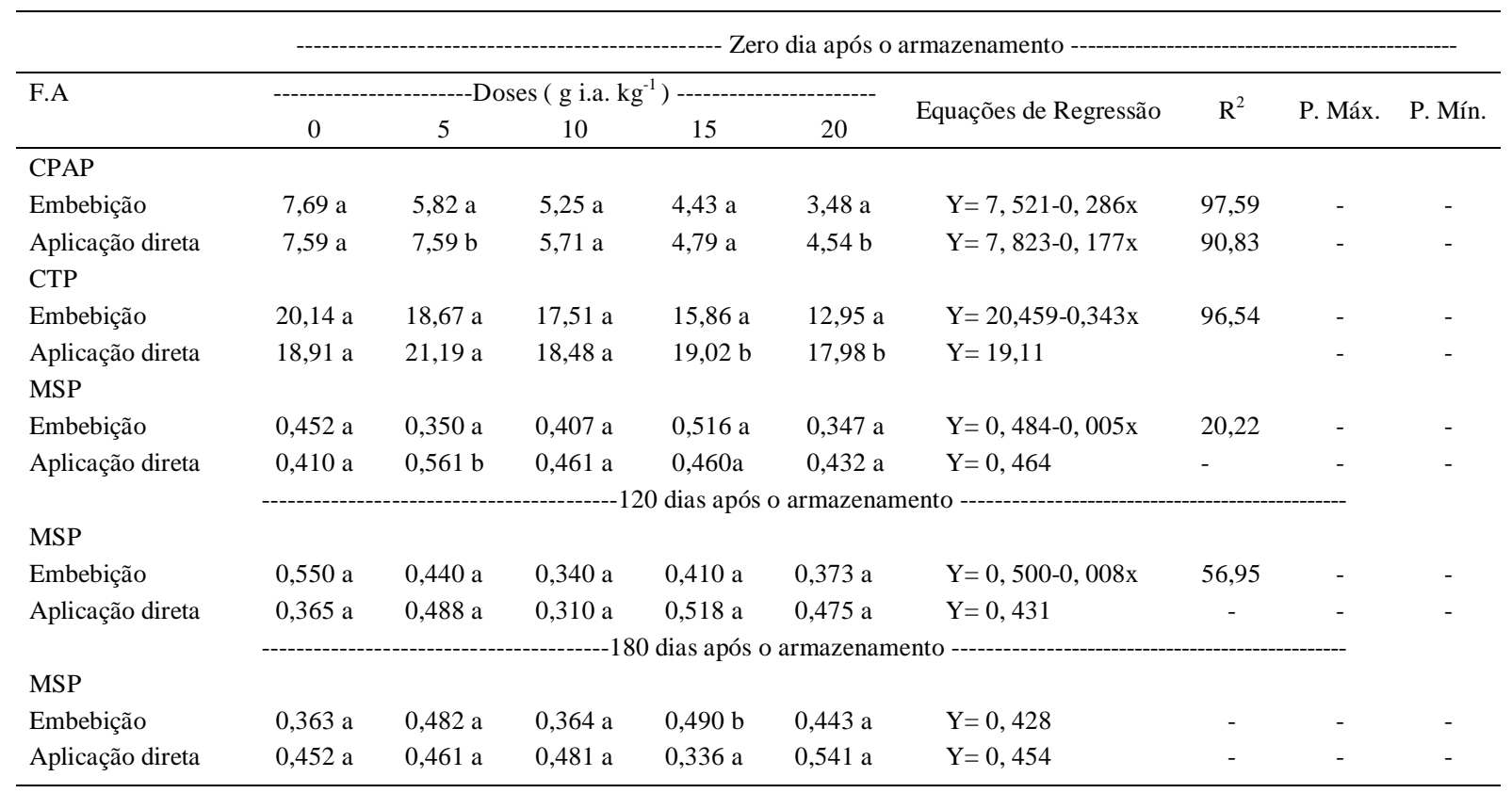

Médias seguidas de mesma letra na coluna não diferem pelo teste de Tukey a 5\% de probabilidade.

ns - não significativo.

períodos de 120, 150 e 180 dias, com ajustes lineares decrescentes com o incremento das doses (Tabela 2). Para a avaliação no período zero, constatou-se interação em função das formas e doses aplicadas, com ajuste linear decrescente para o tratamento via embebição (Tabela 3). NAGASHIMA et al. (2010), em análise ao comprimento de plântulas de algodoeiro originadas de sementes embebidas com cloreto de mepiquat em função das doses, observaram redução do comprimento total das plântulas, comprovando assim que a embebição reduz a altura da planta a partir da fase de plântula.

Com relação à massa seca de plântulas, foram verificadas diferenças significativas quanto à forma de aplicação, com valores inferiores para o tratamento via embebição, quando utilizada a dose $5 \mathrm{~g}$ i.a. $\mathrm{kg}^{-1}$ no período zero. O efeito das doses pode ser explicado por uma equação linear decrescente para o tratamento via embebição, enquanto no tratamento via aplicação direta não houve efeito de doses aplicadas, o mesmo ocorreu no período de 120 dias. Os resultados obtidos corroboram LAMAS et al. (2000), que também observaram redução na massa seca de folhas, por meio de pulverizações foliares parceladas, e com NAGASHIMA et al. (2005), quando utilizaram sementes tratadas via embebição e observaram que o uso de cloreto de mepiquat em doses acima de 2,5\% reduziu a área foliar e a massa seca da parte aérea de plantas de algodoeiro.

O uso de redutores de crescimento na cultura do algodoeiro é crescente em virtude dos sistemas de produção utilizados na cultura atualmente e a obtenção de plantas com menor porte é fundamental, principalmente para o sucesso do sistema adensado de cultivo.

A aplicação do regulador de crescimento tradicionalmente é realizada via foliar, porém, nesse método, há algumas desvantagens como a perda do produto, caso ocorram chuvas após a aplicação, e a necessidade de várias aplicações para um controle efetivo da altura das plantas, interferindo nos custos de produção. Dessa forma, os resultados obtidos confirmam a possibilidade de uso do tratamento de sementes como forma de aplicação do cloreto de mepiquat no controle do crescimento inicial da planta.

Dentre as formas de aplicação via semente, a aplicação direta tem a vantagem de ser executada mais rápido, devido ao menor volume de solução utilizada, o que facilita o processo de secagem após o tratamento. Embora ainda necessite de estudos, o método da aplicação direta oferece, ainda, a possibilidade de poder ser conciliado com o tratamento 
de sementes com fungicida, usualmente realizado previamente à semeadura ou ao armazenamento das sementes.

\section{CONCLUSÃO}

Sementes tratadas com cloreto de mepiquat, independente da forma e dose utilizada, podem ser armazenadas por até 180 dias após tratamento sem comprometer o processo de germinação e a ação do regulador de crescimento.

O tratamento via embebição de sementes com o cloreto de mepiquat assegura a maior redução do crescimento da plântula em relação à aplicação direta.

$\mathrm{O}$ incremento nas doses de cloreto de mepiquat interfere positivamente na redução do crescimento e desenvolvimento das plântulas de algodoeiro, proporcionando menor comprimento e massa seca.

\section{AGRADECIMENTO}

À Coordenação de Aperfeiçoamento de Pessoal de Nível Superior (CAPES), pela concessão de bolsa ao primeiro autor, e à Fundação Araucária, pelo financiamento dos equipamentos de laboratório aprovados junto a este projeto.

\section{REFERÊNCIAS}

ASSOCIATION OF OFFICIAL SEED ANALYSTS (AOSA). Seed vigor testing handbook. East Lansing, 1983. 88p. (Contribution, 32). Disponível em: <http://www.abrates.org.br/ revista/artigos/2000/ v22n2/artigo23.pdf>. Acesso em: 29 mar. 2010 .

BRASIL, Ministério da Agricultura, Pecuária e Abastecimento. Regras para análise de sementes. Secretaria de Defesa Agropecuária. Brasília: MAPA/ACS, 2009. 395p. Disponível em: http://extranet.agricultura.gov.br/php/proton/cultivarweb/ cultivares_protegidas.php. Acesso em: 13 mar. 2010.

GUTHRIE, D. et al. Pix application strategic. Cotton Today Physiology, v.6, n.4, p.4, 1995. Disponível em: <http:// www.cotton.org/tech/physiology/cpt/Growth/upload/PixApplication-Strategies.pdf $>$. Acesso em: 25 mar. 2010.

LAMAS, F.M. Estudo comparativo entre cloreto de mepiquat e cloreto de chlormequat aplicados em algodoeiro. Pesquisa Agropecuária Brasileira, v.36, n.2, p.265-272, 2001. Disponível em: <http://www.scielo.br/pdf/\%0D/pab/v36n2/ a08v36n2.pdf>. Acesso em: 24 jul. 2010. doi: 10.1590/S0100204X2001000200008.
LAMAS, F.M. et al. Reações do algodoeiro CNPA-ITA 90 ao cloreto de mepiquat. Pesquisa Agropecuária Brasileira, v.35, n.5, p.507-516, 2000. Disponível em: <http:// www.scielo.br/pdf/pab/ v35n3/a15v40n9.pdf>. Acesso em: 30 maio, 2010. doi: 10.1590/S0100-204X2000000300005.

MATEUS, G.P. et al. Perdas de cloreto de mepiquat no algodoeiro por chuva simulada. Pesquisa Agropecuária Brasileira, v.39, n.7, p.631-636, 2004. Disponível em: <http:// www.scielo.br/pdf/pab/v39n7/21304.pdf>. Acesso em: 30 maio, 2010. doi: 10.1590/S0100-204X2004000700003.

NAGASHIMA, G.T. et al. Desenvolvimento de plantas de algodão provenientes de sementes embebidas em cloreto de mepiquat. Pesquisa Agropecuária Brasileira, v.40, n.9, p.943-946, 2005. Disponível em: <http://www.scielo.br/pdf/ pab/ v40n9/a15v40n9.pdf>. Acesso em: 21 jul. 2009. doi: 10.1590/S0100-204X2005000900015.

NAGASHIMA, G.T. et al. Embebição de sementes e aplicação foliar com cloreto de mepiquat no crescimento e produção do algodoeiro. Ciência e Agrotecnologia, v.31, n.4 p.10271034, 2007. Disponível em: <http://www.scielo.br/pdf/cagro/ v31n4/13.pdf>. Acesso em: 25 jan. 2010. doi: 10.1590/S141370542007000400013 .

NAGASHIMA, G.T. et al. Desenvolvimento do algodoeiro em resposta a modo de aplicação e doses de cloreto de mepiquat via sementes. Ciência Rural, v.40, n.1 p.7-11, 2009. Disponível em: <http://www.scielo.br/pdf/cr/v40n1/a421cr1926.pdf >. Acesso em: 25 maio, 2010. doi: 10.1590/S010384782009005000236 .

NAGASHIMA, G.T. et al. Qualidade fisiológica e armazenamento de sementes de algodão embebidas em solução de cloreto de mepiquat. Ciência e Agrotecnologia, v.34, n.3, p.681-687, 2010. Disponível em: <http://www.scielo.br/ pdf/cagro/v31n4/13.pdf $>$. Acesso em: 03 jun. 2010. doi: 10.1590/S1413-70542010000300022.

NAKAGAWA, J. Testes de vigor baseados na avaliação das plântulas. In: KRZYZANOWSKI, F.C. et al. Vigor de sementes: conceitos e testes. Londrina: ABRATES, 1999. p.2.1-2.21. Disponível em: <http://www.abrates.org.br/revista/ artigos/1999/v21n1/artigo06.pdf>. Acesso em: 03 nov. 2009.

SOUZA, R.N. et al. Modos de aplicação do cloreto de mepiquat em duas variedades de algodoeiro herbáceo. In: CONGRESSO BRASILEIRO DE ALGODÃO, 5., 2005, Salvador Ba. Resumos... Campina Grande: EMBRAPA Algodão, 2005. (CDROM).

YEATES, S.J. et al. Cotton growth and yield after seed treatment with mepiquat chloride in the tropical season. Field Crop Research, v.93, n.2-3, p.122-131, 2005. 